\title{
The Role of Openly Communicated Motives During the Rationalization Process of Irrigation System Buying Behaviour
}

\section{A Bisschoff}

Graduate School of Management, Potchefstroom University for CHE

\section{ABSTRACT}

The article deals with the identification of the openly stated motives which farmers give to rationalize their buying behaviour in the mechanized irrigation industry. These motives are, in declining order of importance, "Dealership orientation", "Terrain suitability", "Maintenance", "Management", "Mechanical performance", "Design", "Delivery schedule", "Finance", "Infrastructure", "Technical specifications" and "Professional influences". Openly communicated motives are important to agricultural economists, financial and other advisory institutions since they can render better quality services to farmers if they know what are the reasons overtly given to rationalize other unspoken motives. The farmers can benefit from the results since they would be able to examine their own line of thought, and thus identify the motives of real importance applicable to their situation. Marketers of irrigation systems can also benefit since their selling approach would be more motive-directed.

\section{INTRODUCTION}

The article addresses the openly communicated motives which consumers employ in their buying behaviour with regard to a mechanized irrigation system. Bisschoff \& Marais (1991) identified the underlying motives (or unspoken motives) which play a role in the consumer's buying behaviour. Both these sets of motives are important since the consumer employs the openly communicated motives to rationalize the unspoken motives (Ciba-Geigy, 1991). A practical explanation of 
such a state of affairs could be that a person may claim that he bought an expensive German vehicle due its vast "safety features" and "durability" (communicated motives), while the motives which are not communicated openly may be those of "status" and "prestige". The significance of this state of affairs resides in the fact that the consumer does not regularly communicate his real motives to the other people involved, and looks for other "arguments" (or motives) to rationalize his purchase of the German vehicle. These motives are also used by the buyer to rationalize the purchase decision to himself, and play a significant role in the final purchasing decision. It is also important to note that if a strong underlying motive exists while the rationalization motives are absent, the buyer will seldom enter into the final stage of buying behaviour, namely the actual purchase of the product (Ciba-Geigy, 1991). The astute marketer would therefore attempt to identify the underlying motives at first, and then address the rationalization motives to obtain the actual sale. This article addresses the rationalization motives which pertain to the mechanized irrigation industry.

The new irrigation area in the Upper Fish River Valley served as the geographical area for the empirical research. The farmers were new to irrigation farming. Water rights were allocated there from the Orange-Fish River Tunnel during the course of 1987/88 (Bisschoff, 1989: 2). Advanced mechanized irrigation systems consist mainly of centre pivot and linear systems. Both systems are technically highly advanced and apart from their main function of watering crops, they have a vast number of features and safety devices.

The dualistic influence of motives in buying behaviour calls for a study of consumer motives, and since the underlying motives have already been discussed, the logical question remains the determination of the openly communicated motives which are employed to rationalize buying behaviour. Readers can examine the theoretical base which applies to the empirical results by reading the mentioned article by Bisschoff \& Marais (1991).

\section{PROBLEM DEFINITION}

The major concern dealt with in the article pertains to the rationalization effect which motives have on buying behaviour. The first problem refers to the identification of the underlying motives of the farmer in the mechanized irrigation industry, while the second problem deals with the rationalization role these openly communicated motives play in buying behaviour. Since the first problem was 
already addressed by Bisschoff \& Marais (1991), this article logically deals only with the rationalization motives of the farmers.

\section{METHODOLOGY}

The sampling frame consisted of farmers in the Upper Fish River Valley. Simple random sampling was employed to select the respondents for the research, and 48 farmers agreed to participate. A pilot study was conducted with 15 selected farmers to determine the initial set of motives they had employed when they purchased their mechanized irrigation systems (Bisschoff, 1988). The motives identified by the focus group were listed and used to compile a structured questionnaire which was used in the study. In the structured questionnaire the respondents had to record their responses on a seven point Likert-scale to indicate the importance of each motive in their purchasing decision. These motives were presented in statement format in the questionnaire. Personal interviews were conducted with the farmers to ensure that information required in the questionnaire was recorded accurately. A total of 46 questionnaires were usable. The sample amount is in excess of $80 \%$ of the mechanized irrigation farmers in the geographical area.

The list of openly communicated motives were identified from the completed questionnaires by means of principle factor analysis, employing the rotational method "varimax". A cut-off communal value of 1 was used as filter to eradicate less significant statements from the interpretation of the data (Comrey, 1973: 223). However, since factor analysis is especially designed to identify underlying (or in this case "unspoken" motives), the factor loadings are not used as a classification tool (Bisschoff, 1992: 165). The communal values of each statement was calculated and employed to categorize each motive. The communal values were calculated by the squared sum of the individual factor loadings per statement (Bisschoff, 1992: 163). The variance explained by each statement is portrayed by dividing the communality by the number of statements (Wherry, 1984: 290; Yates, 1987:295-305). This value is shown in a percentage format. In addition the variance of each specific motive was calculated. In essence, the communal value, which represents the variance explained by each specific statement, was employed to determine each motive's relative importance. 


\section{EMPIRICAL RESULTS}

The communality values of the statements were used to determine the importance of each statement. Since this study returned relatively high communalities as a result of the high factor loadings, most of the forty-eight statements explained a variance between $1.7 \%$ and $2.5 \%$, and very few were eliminated by the initiated cut-off filter.

The following 11 openly communicated motives were identified and labelled. These motives and their variance explained are shown in Table 1. Short discussions of each identified motive explains the labelling of these motives. The importance of the motives is portrayed by the variance explained in each case and they are discussed in descending order of importance.

Table 1: Openly Communicated Motives

\begin{tabular}{|l|l|l|}
\hline Motive & $\begin{array}{l}\text { Variance } \\
\text { Explained }\end{array}$ & $\begin{array}{l}\text { Cumulative } \\
\text { Variance } \\
\text { Explained }\end{array}$ \\
\hline Dealership Orientation & $11.91 \%$ & $11.91 \%$ \\
\hline Terrain Suitability & $11.90 \%$ & $23.81 \%$ \\
\hline Maintenance & $10.21 \%$ & $34.02 \%$ \\
\hline Management & $10.15 \%$ & $44.17 \%$ \\
\hline Mechanical Performance & $8.31 \%$ & $52.48 \%$ \\
\hline Design & $8.18 \%$ & $60.66 \%$ \\
\hline Delivery Schedule & $8.14 \%$ & $68.80 \%$ \\
\hline Finance & $8.07 \%$ & $76.87 \%$ \\
\hline Infrastructure & $7.89 \%$ & $84.76 \%$ \\
\hline Technical Specifications & $6.19 \%$ & $90.95 \%$ \\
\hline Professional Influences & $6.14 \%$ & $97.09 \%$ \\
\hline
\end{tabular}




\section{Dealership orientation}

"Dealership orientation" relates to the statements regarding the consumer's relationship with the dealer, as well as the dealer's reputation which implies future expectations from the dealer (for instance: will the dealer still be in business to provide after-sales service?). The motive identified as "Dealership orientation" indicates that the farmers use this motive as rationalization of their choice of irrigation system since the different dealers stock differently designed irrigation systems. The farmer could also claim that he bought an irrigation system from a specific dealer because the dealer would still be in available as a future business contact.

\section{Terrain suitability}

As expected, farmers regard the suitability of the terrain as extremely important. The soil as medium for vegetated growth should be of a high quality if the farmer plans to irrigate it. Consumers of advanced irrigation systems, therefore, regard the continual high quality of the soil as an important issue before erecting such an irrigation system. The motive explains a high variance of $11.90 \%$.

\section{Maintenance}

"Maintenance" explains $10.21 \%$ of the total variance explained, and relates to speedy repairs, availability of spares, quality of workmanship, as well as the cost of the repair package. In escence, "Maintenance" relates to the after-sales service provided by the dealer. Surely, a successful selling approach should incorporate this motive as rationale since the fact that the farmers identified "Maintenance" as a motive indicates that they do not expect the irrigation system to supply lengthy, trouble-free service, but they rather expect the irrigation system to break down and wear out certain parts. 


\section{Management}

The ease of managing advanced irrigation systems is valued by farmers as an important motive. This can be seen by the high variance of $10.51 \%$ explained by the motive. Nearly all the statements regarding managerial aspects indicated that on an irrigation farm productivity is deemed to be of the utmost importance. The managerial motive specifically applies to the area since a large percentage of the respondents acquired irrigation systems to supplement their current farming activities, thus increasing the amount of work on the farm.

\section{Mechanical performance}

Issues regarding the macro-design aspects identified the mechanical performance of the irrigation system. Although closely related to the previously mentioned motive, the mechanical performance of the irrigation system also incorporates the structural composition as a motive. "Mechanical performance" explains $8.31 \%$ of the total variance.

\section{Design}

The actual design of the system, thus the type of sprinklers used at which pressure rating, as well as the watering capacity, relates to the micro-design issues and explains $8.18 \%$ of the explained variance. These issues are related to the physical distribution of the irrigation water, and clearly differs from "Mechanical performance" which refers to structural design.

\section{Delivery schedule}

"Delivery schedule" relates to the punctual delivery and activation of the irrigation system. It seems that farmers, therefore, plan their acquisition in order to erect the system shortly prior to the planting season, thus eliminating an unproductive period before the planting season. "Delivery schedule" explains $8.14 \%$ of the total variance. 


\section{Finance}

Quite surprisingly, consumers do not deem "Finance" as one of the most important motives (explaining only $8.07 \%$ of the total variance). However, within the financial scenario, consumers deem the possibility of a hire-purchase or lease agreement more important than the original purchase price. Of further importance to consumers is the length of the financing period once the irrigation system is bought on such an agreement. It seems, therefore, that farmers are more concerned with the availability of credit, than with the purchase price itself. The employment of this motive as a rationale is a serious concern and calls for a warning to farmers who employ it to rationalize their purchase of an irrigation system. This is especially true since the initial purchase price determines the loan repayment amount. Fortunately, this motive is not one of the more important motives identified by the farmers.

\section{Infrastructure}

An existing infrastructure is identified as a motive by farmers wishing to erect an advanced mechanized irrigation system. Although "Infrastructure" explains $7.89 \%$ of the total variance explained, a reason for such a relatively low declaration may be the fact that farmers had grown accustomed to facilities such as electric power and unrestricted water quotas (especially in a specific area where water restrictions have never been introduced).

\section{Technical specifications}

Consumers regard "Technical specifications" as a less important motive (6.19\%) because automation is not regarded as a necessity during the acquisition of an advanced mechanized irrigation system. For instance, the system does not need to shut down automatically, because it can be shut down manually. 


\section{Professional influences}

Farmers do not deem advice from professionals as important once they enter the buying behaviour activities of advanced mechanized irrigation systems. "Professional influences" explains only $6.14 \%$ of the total variance explained, which incidentally, is the lowest percentage of variance explained.

The various motives contributed to explain a curnulative variance of $97.1 \%$ which is regarded as a favorable declaration of variance.

Table 1 highlights the fact that the motives decline in their contribution to the declaration of the variance explained. "Dealership orientation" and "Terrain suitability", therefore, explain a larger part of the explained variance than any other motive, while "Professional influences" proportionally explains the least.

\section{CONCLUSION AND RECOMMENDATION}

The identified motives provide a simple framework which could be used as a guideline by different marketing institutions, agricultural economists and other advice-rendering instiutions since it clarifies the intricate decision-making process with regard to the irrigation industry. The irrigation industry could, furthermore, employ the obtained results to develop strategies for market segmentation, promotion, positioning. and the training of sales personnel. This simplification of the initial set of data set certainly reduces the number of motives, creating a more concise and manageable framework.

The established framework could also aid consumers to understand decisionmaking in the advanced mechanized irrigation industry. One would like to see marketers as well as consumers making use of the analyses to aid them in their buying and selling behaviour.

It is significant that their contribution to the variance explained, decreases from the first motive to the last, with "Dealership orientation" and "Terrain suitability" being the most important while "Professional influences" is the least important of the identified motives. This phenomenon results in the recommendation that marketers of mechanized irrigation systems attempt to address the more important motives first, as farmers deem them the more important considerations during the buying process. Additionally, by moving from the motives explaining the higher percentage of variance to those explaining 
less, the marketer could obtain better salesman-productivity because the more important considerations are addressed prior to the less important ones.

By dealing with the motives on an individual and on a group basis. marketers should be able to comprehend the market in the advanced mechanized irrigation industry better, and should therefore be able to optimize their sales efforts.

Finally, a pitfall in the absolution of the results resides in the fact that the openly communicated motives for buying behaviour were identified. Due to the psychological rationalization process, these motives, or the order thereof, may not always be the true (or unspoken/hidden) motives. The example of the expensive German vehicle mentioned in the introductory section of this article should be kept in mind. However, openly communicated motives remain important in actual selling behaviour of sales personnel. In the case of the worst scenario of using openly communicated motives, the salesperson supplies the buyer with rationalizations which the buyer could use in his psychological framework (Lewison, 1996: 142). The buying behaviour thus becomes rational since it can be motivated and explained (Williams, 1982: 14-16).

\section{NOTE}

I wish to acknowledge the financial assistance of the Centre for Science Development of the Human Sciences Research Council.

\section{REFERENCES}

1. BISSCHOFF, C.A. (1988). Evaluation criteria employed by consumers of centre pivot and linear irrigation systems. BComm (Honors) thesis. Pretoria, UNISA.

2. BISSCHOFF, C.A. (1989). Consumer purchasing behaviour in the advanced mechanized irrigation industry - a factor analysis. MComm thesis. Pretoria, UNISA.

3. BISSCHOFF, C.A. (1992). Factor identification in the agricultural tractor industry. DComm dissertion. Pretoria, UNISA. 
4. BISSCHOFF, C.A \& MARAIS, A de K. (1991). Factor identificarion - an analysis of buyer behaviour during the acquisition of an advanced mechanized irrigation system. Agrekon, Vol. 30(4): 237-240.

5. CIBA-GEIGY (1991). Advanced sales communication training course. Northwestern Co-operative, Lichtenburg.

6. COMREY, A.L. (1973). A first course in factor analysis. New York, Academic State Press.

7. LEWISON, D.M. (1996). Marketing Management. New York, Dryden Press.

8. WILLIAMS, T.G. (1982). Consumer behavior-fundamentals \& strategies. New York, West Publishing.

9. WHERRY, R.J. (1984). Contributions to correlation analysis. San Francisco, Academic Press.

10.YATES, A. (1987). Multivariate exploratory data analysis. New York, University State Press. 